\title{
Yaygın Mürdümük (Lathyrus sativus L.) Genotiplerinin Yarı Kurak İklim Koşullarında Bazı Tarımsal Özellikleri ile Verim Performanslarının Belirlenmesi
}

\author{
Mehmet Arif Özyazıc1 ${ }^{*}$, Semih Açıkbaş² \\ ${ }^{1}$ Siirt Üniversitesi, Ziraat Fakültesi, Tarla Bitkileri Bölümü, Siirt, Türkiye (ORCID: 0000-0001-8709-4633) \\ ${ }^{2}$ Siirt Üniversitesi, Ziraat Fakültesi, Tarla Bitkileri Bölümü, Siirt, Türkiye (ORCID: 0000-0003-4384-3908)
}

(İlk Geliş Tarihi 5 Aralık 2019 ve Kabul Tarihi 30 Aralık 2019)

(DOI: $10.31590 /$ ejosat.655662)

\begin{abstract}
ATIF/REFERENCE: Özyazıc1, M.A., \& Açıkbaş, S. (2019). Yaygın Mürdümük (Lathyrus sativus L.) Genotiplerinin Yarı Kurak İklim
\end{abstract} Koşullarında Bazı Tarımsal Özellikleri ile Verim Performanslarının Belirlenmesi. Avrupa Bilim ve Teknoloji Dergisi, (17), 1058-1068.

$\ddot{\mathbf{O z}}$

Bu araştırmada, yaygın mürdümük (Lathyrus sativus L.) genotiplerinin Türkiye’nin yarı kurak iklimine sahip Güneydoğu Anadolu Bölgesi koşullarında bazı agronomik özellikleri ile ot ve tohum verimlerinin belirlenmesi amaçlanmıştır. Araştırma, Siirt Üniversitesi Ziraat Fakültesi, Araştırma ve Uygulama Arazisi'nde 2016-2017 yıllarında yürütülmüştür. Bitkisel materyal olarak 22 yaygın mürdümük genotipi ve 2 adet tescilli çeşit kullanılmış olup; tarla denemeleri, tesadüf blokları deneme desenine göre 3 tekrarlamalı olarak kurulmuştur. Çalışmada parsellerin yarısı ot, diğer yarısı da tohum verimine ait parametrelerin belirlenmesi için ayrılmıştır. Araştırmada; doğal bitki boyu, ana sap uzunluğu, ana sap sayısı, yeşil ot verimi, kuru ot verimi, bitkide bakla sayısı, baklada tane sayısı, bin tane ağırlığı, tohum verimi, biyolojik verim ve hasat indeksi verileri alınmıştır. Araştırma sonucuna göre; doğal bitki boyunun 38.35$44.87 \mathrm{~cm}$, ana sap uzunluğunun 55.25-61.82 cm, ana sap sayısının 3.20-4.70 adet/bitki, yeşil ot veriminin 1348.1-1890.4 kg/da, kuru ot veriminin 331.1-448.4 kg/da, bitkide bakla sayısının 11.3-17.7 adet, baklada tane sayısının 2.0-3.1 adet, bin tane ağırlığının 79.36$125.87 \mathrm{~g}$, tohum veriminin 101.3-194.5 kg/da, biyolojik verimin 444.8-707.5 kg/da ve hasat indeksinin \% 18.3-\% 36.4 arasında değiştiği tespit edilmiştir. Elde edilen sonuçlara göre; ot üretimi için ETH WIR-70 ve IFLS 257, tohum üretimi için ise Sel 1794 genotiplerinin öne çıktığı belirlenmiştir. Araştırma sonucunda, öne çıkan ve/veya ümitvar olan genotiplerin tarla denemelerinin devam ettirilmesinin uygun olacağı ve bölgeye uygun yeni çeşitlerin geliştirebileceği öngörülmektedir.

Anahtar Kelimeler: Mürdümük, Kuru ot verimi, Tohum verimi, Biyolojik verim, Hasat indeksi.

\section{Determination of Some Agricultural Characteristics and Yield Performance of Common Grasspea (Lathyrus sativus L.) Genotypes in Semi-Arid Climate Conditions}

\begin{abstract}
This research was conducted to determine some agronomic characteristics, herbage yield and seed yield of common grasspea (Lathyrus sativus L.) genotypes under semi-arid climate conditions in Turkey's Southeastern Anatolia Region. This study was carried out in research and application field of Faculty of Agriculture, Siirt University in 2016-2017. In this study, 22 common grasspea genotypes and 2 cultivar were used as plant material. Field trials were established with 3 replications according to randomized complete blocks experimental design. In the study, half of the parcels were reserved to determine herbage and other half was reserved for seed yield. In
\end{abstract}

* Sorumlu Yazar: Siirt Üniversitesi, Ziraat Fakültesi, Tarla Bitkileri Bölümü, Siirt, Türkiye, ORCID: 0000-0001-8709-4633, arifozyazici@siirt.edu.tr 
the study, natural plant height, main stem length, main stem number, green forage yield, hay yield, number of pods per plant, number of grains per pod, thousand seed weight, seed yield, biological yield, and harvest index were also investigated. According to results of the study; natural plant height, main stem length, main stem number, green forage yield, hay yield, number of pods per plant, number of grains per pod, thousand seed weight, seed yield, biological yield, and harvest index were ranged between 38.35-44.87 cm, 55.25$61.82 \mathrm{~cm}, 3.20-4.70$ per plant, $1348.1-1890.4 \mathrm{~kg} / \mathrm{da}, 331.1-448.4 \mathrm{~kg} / \mathrm{da}, 11.3-17.7$ per plant, 2.0-3.1 per pod, 79.36-125.87 g, 101.3$194.5 \mathrm{~kg} / \mathrm{da}, 444.8-707.5 \mathrm{~kg} / \mathrm{da}$, and $18.3-36.4 \%$ respectively. According to these results, genotypes ETH WIR-70 and IFLS 257 were suggested for the herbage/hay production, while Sel 1794 was suggested for the seed production. As a result of the research, it is foreseen that field trials of prominent and/or promising genotypes would be appropriate and new varieties suitable for the region could be developed.

Keywords: Grasspea, Hay yield, Seed yield, Biological yield, Harvest index.

\section{Giriş}

Leguminosae familyasına ait olan mürdümük (Lathyrus) cinsi, içerisinde 189 türü barındırmaktadır (Allkin ve ark., 1985). Bu cinsin, neolitik dönemden beri insan ve hayvan beslenmesi amacıyla dünyada en fazla kültürü yapılan türü yaygın mürdümük (Lathyrus sativus)'tür (Hanbury ve ark., 2000; Başaran ve ark., 2007; Ahmadi ve ark., 2015). Yaygın mürdümügün, kuraklığa dayanıklı olması (Tekele-Haimanot ve ark., 1990), tohumların protein içeriğinin yüksek oluşu (Kuo ve ark., 1995; Grela ve ark., 2012) ve bunun yanında hastalık ve zararlılara karşı toleranslı olması (Talukdar ve Biswas, 2008) gibi avantajlı yönleri ile hem yem hem de tohum verimi için yetiştirilen tek yıllık serin mevsim baklagil yem bitkisidir.

Mürdümük türleri, başta Doğu ve Güney Doğu Anadolu bölgeleri ile Orta Karadeniz Bölgesi olmak üzere Türkiye'nin doğal florasında yaygın şekilde yetişmesine (Kılınç ve Özen, 1988a; Kılınç ve Özen, 1988b; Kutbay ve ark., 1995) rağmen, Türkiye'de oldukça sınırlı alanda tarımı yapılmaktadır. Bununla birlikte; kıraç topraklara ve kuraklığa karşı dayanıklılığı, tarımında daha az girdiye ihtiyaç duyması, Türkiye'de en çok tarımı yapılan yem bitkisi içerisinde yer alan yaygın fiğ (Vicia sativa L.) ile mukayese edildiğinde daha verimli olması, önemli bir ekim nöbeti ve yeşil gübre bitkisi olması, karışık ekimlerindeki üstünlükleri gibi tarımsal faydaları dikkate alındığında çiftçiler tarafından kolayca benimsenebileceği ve tarımının yaygınlaştırılabileceği belirtilmiştir (Fırıncıoğlu ve ark., 2004). Bu amaçla Türkiye'nin farklı ekolojilerinde yürütülen araştırmalardan (Sabancı ve Özpınar, 2000; Balabanlı ve Kara, 2003; Karadağ ve ark., 2004, 2012; Kökten ve Bakoğlu, 2011; Sayar ve Han, 2015; Öten ve ark., 2017) olumlu sonuçlar alınmış, yaygın mürdümüğün ot verimi ve kalitesi ile tohum üretimi amacıyla yetiştirilebilecek alternatif bir yem bitkisi olduğu ifade edilmiştir.

Gelişmiş ülkelerde tarla tarımı içerisinde yem bitkilerinin ekiliş oranı \% 25-30'larda iken, bu oran Türkiye'de \% 8-10 civarındadır. Bu oranı arttırabilmek için, yetiştiriciliği yapılan mevcut yem bitkisi tür ve çeşitlerin tarımı ile ilgili bir dizi kültürel işlemlerin doğru ve zamanında yapılmasının yanı sıra; alternatif olabilecek yem bitkisi cins ve/veya türlerin ortaya konulması, yeni çeşitlerin geliştirilmesi ve geliştirilen çeşitlerin farklı ekolojilerde adaptasyon çalışmalarının yapılması da büyük önem taşımaktadır.

Bu çalışmada, tarla tarımı içerisinde yetiştirilebilme potansiyeli yüksek olan yaygın mürdümük (L. sativus L.) bitkisine ait bazı genotiplerin, Türkiye'nin yarı kurak iklim koşullarına sahip Güneydoğu Anadolu Bölgesi'nde ot ve tohum verimi ile verime etkili bazı unsurlarının belirlenmesi amaçlanmıştır.

\section{Materyal ve Metot}

Araştırma; 2016 ve 2017 yıllarında, Türkiye’nin Güneydoğu Anadolu Bölgesi'nde yer alan Siirt ili ekolojik koşullarında yürütülmüştür (Şekil 1). Uzun yıllar (1970-2017) meteorolojik verilerine göre (Anonim, 2017) Siirt ili ikliminin yarı kurak olduğu anlaşılmaktadır. Yörede uzun yıllar sıcaklık ortalaması $16.2{ }^{\circ} \mathrm{C}$ iken; araştırma yıllarındaki (2016 ve 2017) ortalama sıcaklık değerleri sırasıyla $17.1{ }^{\circ} \mathrm{C}$ ve $17.2^{\circ} \mathrm{C}$ olarak gerçekleşmiştir. Araştırma yıllarındaki toplam yağış miktarları sırasıyla $775.0 \mathrm{~mm}$ ve $552.0 \mathrm{~mm}$ olarak gerçekleşmiş olup, uzun yıllar toplam yağış ortalaması ise $647.0 \mathrm{~mm}$ olarak kaydedilmiştir. Ortalama nispi nem değerleri açısından, araştırma yılları ile uzun yıllar ortalamalarının birbirlerine yakın olduğu görülmektedir (Tablo 1).

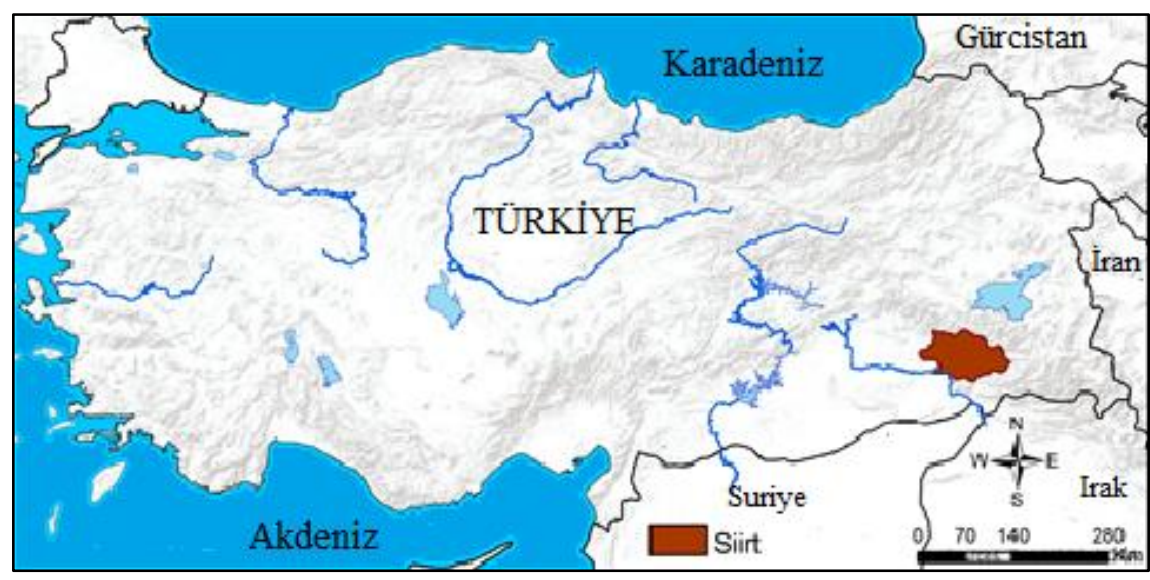

Şekil 1. Araştırma Alanı Lokasyon Haritası 


\begin{tabular}{|c|c|c|c|c|c|c|c|c|c|c|c|c|c|}
\hline Rasat Yılları/Aylar & 䔍 & 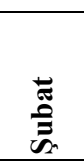 & 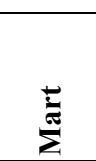 & 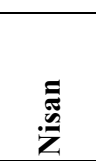 & $\sum_{\sum}^{\infty}$ & $\underset{\mathbb{N}}{\mathbb{N}}$ & き & 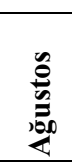 & 济 & $\frac{\Xi}{\frac{1}{x}}$ & 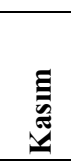 & $\frac{\mathscr{y}}{\bar{E}}$ & 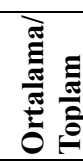 \\
\hline \multicolumn{14}{|c|}{ Ortalama Sicaklık $\left({ }^{\circ} \mathrm{C}\right)$} \\
\hline 2016 & 1.7 & 8.1 & 10.1 & 16.6 & 19.9 & 26.5 & 31.4 & 32.3 & 25.0 & 19.5 & 10.4 & 3.3 & 17.1 \\
\hline 2017 & 3.0 & 2.7 & 9.6 & 14.0 & 19.5 & 26.9 & 32.3 & 32.0 & 28.4 & 18.4 & 11.2 & 8.0 & 17.2 \\
\hline $1970-2017$ & 2.8 & 4.4 & 8.7 & 14.1 & 19.5 & 26.2 & 30.6 & 30.1 & 25.2 & 18.1 & 10.3 & 4.7 & 16.2 \\
\hline \multicolumn{14}{|c|}{ Nispi Nem (\%) } \\
\hline 2016 & 76.2 & 68.3 & 62.3 & 47.5 & 48.9 & 32.7 & 24.5 & 20.5 & 29.8 & 36.8 & 49.7 & 73.1 & 47.5 \\
\hline 2017 & 65.9 & 64.9 & 63.9 & 59.5 & 51.7 & 29.5 & 19.0 & 19.0 & 19.1 & 34.6 & 64.4 & 65.2 & 46.4 \\
\hline $1970-2017$ & 70.5 & 65.6 & 60.3 & 57.3 & 49.2 & 34.0 & 26.8 & 26.1 & 31.0 & 47.2 & 62.2 & 70.1 & 50.0 \\
\hline \multicolumn{14}{|c|}{ Toplam Yağıș Miktarı (mm) } \\
\hline 2016 & 196.8 & 63.8 & 136.6 & 66.8 & 64.7 & 20.6 & 2.4 & 0.2 & 19.0 & 27.1 & 55.6 & 121.4 & 775.0 \\
\hline 2017 & 46.4 & 29.2 & 119.2 & 132.8 & 74.6 & 0.0 & 0.0 & 0.4 & 0.0 & 5.2 & 97.0 & 48.2 & 552.0 \\
\hline $1970-2017$ & 72.9 & 89.9 & 98.9 & 96.7 & 59.5 & 9.7 & 3.1 & 2.3 & 4.7 & 47.9 & 77.8 & 83.6 & 647.0 \\
\hline
\end{tabular}

Araştırmada, tarla denemesi kurulmadan önce 0-20 cm derinlikten alınan toprak örneklerinin analiz sonuçları Tablo 2'de verilmiştir. Tablo 2 incelendiğinde; her iki yıla ait araştırma topraklarının tuzsuz, hafif alkali karakterde, kireçli-orta kireçli ve alınabilir potasyum (K) içeriklerinin yeterli düzeyde olduğu saptanmıştır. Birinci yıl toprakları killi tekstürlü, organik madde kapsamı az, alınabilir fosfor (P) kapsamı ise çok az düzeyde; ikinci yıl toprakları ise killi-tın tekstürlü, organik madde ve alınabilir P kapsamı orta düzeydedir (Tablo 2).

Tablo 2. Araştırma Yeri Topraklarının Bazı Fiziksel ve Kimyasal Özellikleri*

\begin{tabular}{lcc}
\hline \multirow{2}{*}{ Toprak Özelliği } & \multicolumn{2}{c}{ Değeri } \\
\cline { 2 - 3 } Kum, \% & 2016 yılı deneme yeri & 2017 yılı deneme yeri \\
Kil, \% & 14.00 & 39.84 \\
Silt, \% & 58.00 & 34.16 \\
pH & 28.00 & 26.00 \\
Elektriksel İletkenlik, dS/m & 7.95 & 7.53 \\
Kireç $\left(\mathrm{CaCO}_{3}\right), \%$ & 0.107 & 0.150 \\
Organik madde, \% & 10.5 & 4.2 \\
Alınabilir $\mathrm{P}, \mathrm{kg} \mathrm{P} \mathrm{O}_{5} / \mathrm{da}$ & 1.35 & 2.22 \\
Alınabilir K, $\mathrm{kg} \mathrm{K} \mathrm{K}_{2} \mathrm{O} / \mathrm{da}$ & 2.3 & 7.9 \\
\hline
\end{tabular}

*: Analizler, Siirt Üniversitesi, Bilim ve Teknoloji Uygulama ve Araştırma Merkezi Laboratuvarı'nda yapılmıştır.

Araştırmada, ICARDA (International Center for Agricultural Research in the Dry Areas)'dan temin edilen 22 hat ile Türkiye'de ıslah edilen 2 çeşit (GAP Mavisi ve Gürbüz-2001) olmak üzere toplam 24 yaygın mürdümük genotipi materyal olarak kullanılmıştır.

Araştırmada tarla denemeleri, tesadüf blokları deneme desenine göre 3 tekrarlamalı olarak kurulmuştur. Her parselde 6 sıra halinde $25 \mathrm{~cm}$ sıra arası mesafe ile ekim yapılmış olup (Anonim, 2019); parsellerin yarısı ot, diğer yarısı ise tohum verimine ait parametrelerin ölçülmesi için planlanmıştır. Buna göre parsel büyüklüğü $1.50 \mathrm{~m}$ x $5.00 \mathrm{~m}=7.5 \mathrm{~m}^{2}$ dir. Dekara $14 \mathrm{~kg}$ ekim normu ile tohum atılmıştır. Toprak analiz sonuçlarına göre ekimle birlikte; ilk yıl $4 \mathrm{~kg} / \mathrm{da}$, ikinci yıl ise $3 \mathrm{~kg} / \mathrm{da}$ saf azot (N) olacak şekilde üre (\% $46 \mathrm{~N}$ ) ve ilk yıl $6 \mathrm{~kg} \mathrm{P}_{2} \mathrm{O}_{5} /$ da saf P olacak şekilde de triple süper fosfat (\% 43-44 P) gübrelemesi yapılmıştır. Araştırmanın ikinci yılında, toprakta alınabilir $\mathrm{P}$ yeterli düzeyde olduğu için fosforlu gübreleme uygulanmamıştır.

Ekimler her iki yılda da Mart ayının ilk yarısında (03.03.2016 ve 14.03.2017) yapılmış; Mayıs ayının ikinci yarısında (15.05.2016 ve 25.05.2017) ot verimi ve ilk yıl için Haziran ayının ikinci yarısında (27.06.2016), ikinci yıl için Temmuz ayının ilk haftasında (03.07.2017) da tohum verimi için hasatlar gerçekleştirilmiştir. Hasat sırasında parsel başlarından 0.5 m’lik kısımlar, parsel kenarlarından ise birer sıra kenar tesiri olarak atılmıştır. Ot verimine ait parametreler tam çiçeklenme döneminde, tohum verimine ait özellikler ise fizyolojik olum döneminde yapılmıştır.

Araştırmada kullanılan genotiplerde; doğal bitki boyu, ana sap uzunluğu, ana sap sayısı, yeşil ve kuru ot verimi, bitkide bakla sayısı, baklada tane sayısı, tohum verimi, bin tane ağırlığı, biyolojik verim ve hasat indeksi Anonim (2019) tarafından bildirilen esaslara göre tespit edilmiştir.

Araştırma sonunda elde edilen verilerde, her bir özellik için homojenlik testi yapılmış olup, varyanslar homojen çıkmıştır. Buna göre iki yıllık veriler tesadüf blokları deneme desenine göre varyans analizine tabii tutulmuş; F testi sonuçlarına göre gruplar arasındaki farklılıklar Tukey çoklu karşılaştırma testi ile belirlenmiştir (Açıkgöz ve Açıkgöz, 2001). 


\section{Araştırma Sonuçları ve Tartışma}

\subsection{Doğal Bitki Boyu}

Doğal bitki boyu yönünden genotipler arasında istatistiksel açıdan çok önemli ( $p<0.01)$ farklılıklar belirlenmiştir. İki yıllık ortalama verilere göre; en yüksek doğal bitki boyu istatistiksel açıdan birinci grupta yer alan ETH WIR-70 (44.87 cm) ve Sel 706 (44.83 cm) genotiplerinde belirlenmiştir. En düşük doğal bitki boyu değeri ise Sel 440 genotipinde (38.35 cm) saptanmıştır. Genotip x yıl interaksiyonu incelendiğinde ise; bazı genotiplerde bitki boyu değerleri yıllara göre dalgalanmalar göstermiş; ilk yıl bazı genotipler yüksek bitki boyu grubunda iken (örneğin, Sel 2329), ikinci yıl aynı genotipler düşük grupta yer almışlardır. Bu nedenle, doğal bitki boyu yönünden genotip x yıl interaksiyonu istatistiksel açıdan çok önemli (p<0.01) bulunmuştur (Tablo 3). Genotipler arasındaki bu boy farklılıkları; Kökten ve Bakoğlu (2011), Sayar ve ark. (2013) ve Seydoşoğlu ve ark. (2015) tarafından da ifade edildiği üzere, genotiplerin genetik yapılarının ve adaptasyon yeteneklerinin farklı olması ile açıklanabilir.

Araştırmanın ilk yılında genotiplerin ortalaması olarak doğal bitki boyu $41.91 \mathrm{~cm}$, ikinci yılında $40.47 \mathrm{~cm}$ olarak saptanmıştır. Yıllar arasındaki bu farklılık istatistiksel açıdan çok önemli $(\mathrm{p}<0.01)$ bulunmuştur (Tablo 3$)$.

Yaygın mürdümük bitkisi ile yapılan araştırmalarda doğal bitki boyunun $37.2 \mathrm{~cm}$ ile $153.0 \mathrm{~cm}$ arasında değişim gösterdiği bildirilmiştir (Bayram ve ark., 2004; Gül ve ark., 2004; Türk ve ark., 2007; Rybinski ve ark., 2008; Bucak, 2009; Kökten ve Bakoğlu, 2011; Sayar ve ark., 2013; Seydoşoğlu ve ark., 2015; Ahmadi ve ark., 2015). Çalışmadan elde edilen doğal bitki boyu değerleri, diğer araştırmacıların elde ettiği bir kısım değerlerle benzerlik gösterirken, bir kısmından düşük bulunmuştur. Bu farklılıkların, araştırmalarda kullanılan genotipler ile denemelerin yürütüldüğü ekolojik koşullardan kaynaklandığı düşünülmektedir.

Tablo 3. Yaygın Mürdümük Genotiplerinde Belirlenen Doğal Bitki Boyu, Ana Sap Uzunluğu ve Ana Sap Sayısına Ait Değerlerl

\begin{tabular}{|c|c|c|c|c|c|c|c|c|c|}
\hline \multirow{2}{*}{ Genotipler } & \multicolumn{3}{|c|}{ Doğal Bitki Boyu (cm) } & \multicolumn{3}{|c|}{ Ana Sap Uzunluğu (cm) } & \multicolumn{3}{|c|}{ Ana Sap Sayısı (adet/bitki) } \\
\hline & 2016 & 2017 & Ortalama & 2016 & 2017 & Ortalama & 2016 & 2017 & Ortalama \\
\hline IFLS 349 & $40.00 \mathrm{efg}$ & $40.00 \mathrm{efg}$ & $40.00 \mathrm{DEF}$ & $56.53 \mathrm{bcd}$ & $56.89 \mathrm{bcd}$ & $56.71 \mathrm{AB}$ & $3.07 \mathrm{ef}$ & 3.33 def & $3.20 \mathrm{E}$ \\
\hline IFLS 257 & $47.33 \mathrm{a}$ & $40.80 \mathrm{~d}-\mathrm{g}$ & $44.07 \mathrm{AB}$ & $58.13 \mathrm{bcd}$ & $57.13 \mathrm{bcd}$ & $57.63 \mathrm{AB}$ & $3.00 \mathrm{f}$ & $3.67 \mathrm{~b}-\mathrm{f}$ & $3.33 \mathrm{DE}$ \\
\hline IFLS 298 & $42.80 \mathrm{a}-\mathrm{e}$ & 38.47 efg & $40.63 \mathrm{~B}-\mathrm{F}$ & $57.33 \mathrm{bcd}$ & 59.44 a-d & $58.39 \mathrm{AB}$ & $3.33 \mathrm{def}$ & $4.00 \mathrm{a}-\mathrm{f}$ & 3.67 B-E \\
\hline IFLS 206 & $40.90 \mathrm{~d}-\mathrm{g}$ & $36.47 \mathrm{~g}$ & $38.68 \mathrm{EF}$ & $56.40 \mathrm{bcd}$ & $55.47 \mathrm{bcd}$ & $55.93 \mathrm{~B}$ & $3.53 \mathrm{~b}-\mathrm{f}$ & $4.33 \mathrm{a}-\mathrm{e}$ & $3.93 \mathrm{~A}-\mathrm{E}$ \\
\hline GAP Mavisi & $41.80 \mathrm{~b}-\mathrm{g}$ & $39.13 \mathrm{efg}$ & $40.47 \mathrm{C}-\mathrm{F}$ & $57.67 \mathrm{bcd}$ & $57.67 \mathrm{bcd}$ & $57.67 \mathrm{AB}$ & $4.00 \mathrm{a}-\mathrm{f}$ & $4.33 \mathrm{a}-\mathrm{e}$ & 4.17 A-D \\
\hline IFLS 968 & $43.13 \mathrm{a}-\mathrm{e}$ & $40.27 \mathrm{efg}$ & $41.70 \mathrm{~A}-\mathrm{F}$ & $57.60 \mathrm{bcd}$ & $59.11 \mathrm{a}-\mathrm{d}$ & $58.36 \mathrm{AB}$ & $4.07 \mathrm{a}-\mathrm{f}$ & $4.33 \mathrm{a}-\mathrm{e}$ & $4.20 \mathrm{ABC}$ \\
\hline Gürbüz-2001 & $43.53 \mathrm{a}-\mathrm{e}$ & $41.80 \mathrm{~b}-\mathrm{g}$ & 42.67 A-D & $58.33 \mathrm{bcd}$ & $60.33 \mathrm{a}-\mathrm{d}$ & $59.33 \mathrm{AB}$ & $3.13 \mathrm{def}$ & $3.67 \mathrm{~b}-\mathrm{f}$ & $3.40 \mathrm{CDE}$ \\
\hline Sel 666 & $42.13 \mathrm{a}-\mathrm{f}$ & $40.73 \mathrm{~d}-\mathrm{g}$ & $41.43 \mathrm{~A}-\mathrm{F}$ & $57.13 \mathrm{bcd}$ & $55.47 \mathrm{bcd}$ & $56.30 \mathrm{AB}$ & $4.00 \mathrm{a}-\mathrm{f}$ & $4.33 \mathrm{a}-\mathrm{e}$ & 4.17 A-D \\
\hline Sel 668 & $40.93 \mathrm{~d}-\mathrm{g}$ & $40.60 \mathrm{~d}-\mathrm{g}$ & 40.77 B-F & $55.60 \mathrm{bcd}$ & 59.07 a-d & $57.33 \mathrm{AB}$ & $4.40 \mathrm{a}-\mathrm{d}$ & $5.00 \mathrm{a}$ & $4.70 \mathrm{~A}$ \\
\hline Sel 676 & $40.47 \mathrm{efg}$ & $41.80 \mathrm{~b}-\mathrm{g}$ & $41.13 \mathrm{~B}-\mathrm{F}$ & $55.73 \mathrm{bcd}$ & $60.73 \mathrm{a}-\mathrm{d}$ & $58.23 \mathrm{AB}$ & $4.00 \mathrm{a}-\mathrm{f}$ & $4.33 \mathrm{a}-\mathrm{e}$ & $4.17 \mathrm{~A}-\mathrm{D}$ \\
\hline Sel 681 & $40.93 \mathrm{~d}-\mathrm{g}$ & $46.60 \mathrm{abc}$ & $43.77 \mathrm{ABC}$ & $55.53 \mathrm{bcd}$ & $63.33 \mathrm{ab}$ & $59.43 \mathrm{AB}$ & $3.40 \mathrm{c}-\mathrm{f}$ & $4.67 \mathrm{abc}$ & $4.03 \mathrm{~A}-\mathrm{E}$ \\
\hline Sel 702 & $40.87 \mathrm{~d}-\mathrm{g}$ & $40.53 \mathrm{efg}$ & 40.70 B-F & $54.80 \mathrm{bcd}$ & $61.11 \mathrm{a}-\mathrm{d}$ & $57.96 \mathrm{AB}$ & $3.13 \mathrm{def}$ & $4.67 \mathrm{abc}$ & 3.90 A-E \\
\hline Sel 706 & $46.00 \mathrm{a}-\mathrm{d}$ & $43.67 \mathrm{a}-\mathrm{e}$ & $44.83 \mathrm{~A}$ & $54.40 \mathrm{~cd}$ & $60.11 \mathrm{a}-\mathrm{d}$ & $57.26 \mathrm{AB}$ & $3.67 \mathrm{~b}-\mathrm{f}$ & $4.67 \mathrm{abc}$ & 4.17 A-D \\
\hline Sel 299 & $41.53 \mathrm{~b}-\mathrm{g}$ & $36.53 \mathrm{~g}$ & $39.03 \mathrm{EF}$ & $57.27 \mathrm{bcd}$ & $53.93 \mathrm{~d}$ & $55.60 \mathrm{~B}$ & $4.13 \mathrm{a}-\mathrm{f}$ & $4.00 \mathrm{a}-\mathrm{f}$ & 4.07 A-D \\
\hline Sel 1837 & $41.00 \mathrm{~d}-\mathrm{g}$ & $36.67 \mathrm{~g}$ & $38.83 \mathrm{EF}$ & $63.27 \mathrm{ab}$ & $55.57 \mathrm{bcd}$ & $59.42 \mathrm{AB}$ & $4.00 \mathrm{a}-\mathrm{f}$ & $4.00 \mathrm{a}-\mathrm{f}$ & $4.00 \mathrm{~A}-\mathrm{E}$ \\
\hline Sel 2267 & $39.53 \mathrm{efg}$ & $39.60 \mathrm{efg}$ & 39.57 DEF & $54.87 \mathrm{bcd}$ & $59.33 \mathrm{a}-\mathrm{d}$ & $57.10 \mathrm{AB}$ & $3.33 \mathrm{def}$ & $4.67 \mathrm{abc}$ & 4.00 A-E \\
\hline Sel 2273 & $41.20 \mathrm{c}-\mathrm{g}$ & $39.53 \mathrm{efg}$ & $40.37 \mathrm{C}-\mathrm{F}$ & $54.27 \mathrm{~cd}$ & $56.22 \mathrm{bcd}$ & $55.25 \mathrm{~B}$ & $3.67 \mathrm{~b}-\mathrm{f}$ & $4.33 \mathrm{a}-\mathrm{e}$ & $4.00 \mathrm{~A}-\mathrm{E}$ \\
\hline Sel 2329 & $43.67 \mathrm{a}-\mathrm{e}$ & $40.47 \mathrm{efg}$ & $42.07 \mathrm{~A}-\mathrm{E}$ & $60.47 \mathrm{a}-\mathrm{d}$ & $60.17 \mathrm{a}-\mathrm{d}$ & $60.32 \mathrm{AB}$ & $4.13 \mathrm{a}-\mathrm{f}$ & $4.00 \mathrm{a}-\mathrm{f}$ & $4.07 \mathrm{~A}-\mathrm{D}$ \\
\hline Sel 385 & $40.40 \mathrm{efg}$ & $39.73 \mathrm{efg}$ & 40.07 DEF & $56.93 \mathrm{bcd}$ & $59.33 \mathrm{a}-\mathrm{d}$ & $58.13 \mathrm{AB}$ & $3.87 \mathrm{a}-\mathrm{f}$ & $4.00 \mathrm{a}-\mathrm{f}$ & 3.93 A-E \\
\hline Sel 421 & $41.87 \mathrm{~b}-\mathrm{g}$ & $41.87 \mathrm{~b}-\mathrm{g}$ & $41.87 \mathrm{~A}-\mathrm{E}$ & $57.80 \mathrm{bcd}$ & 59.56 a-d & $58.68 \mathrm{AB}$ & $4.13 \mathrm{a}-\mathrm{f}$ & $3.67 \mathrm{~b}-\mathrm{f}$ & 3.90 A-E \\
\hline Sel 440 & $39.73 \mathrm{efg}$ & $36.97 \mathrm{fg}$ & $38.35 \mathrm{~F}$ & $54.07 \mathrm{~d}$ & $56.67 \mathrm{bcd}$ & & $4.13 \mathrm{a}-\mathrm{f}$ & $4.00 \mathrm{a}-\mathrm{f}$ & $4.07 \mathrm{~A}-\mathrm{D}$ \\
\hline Sel 1794 & $42.67 \mathrm{a}-\mathrm{e}$ & $41.67 \mathrm{~b}-\mathrm{g}$ & $42.17 \mathrm{~A}-\mathrm{E}$ & $60.33 \mathrm{a}-\mathrm{d}$ & 60.44 a-d & $60.39 \mathrm{AB}$ & $5.00 \mathrm{a}$ & 4.33 a-e & $4.70 \mathrm{~A}$ \\
\hline ETH-24 & $40.60 \mathrm{~d}-\mathrm{g}$ & $40.60 \mathrm{~d}-\mathrm{g}$ & $40.60 \mathrm{~B}-\mathrm{F}$ & $55.33 \mathrm{bcd}$ & $62.89 \mathrm{abc}$ & $59.11 \mathrm{AB}$ & $3.47 \mathrm{~b}-\mathrm{f}$ & $4.33 \mathrm{a}-\mathrm{e}$ & $3.90 \mathrm{~A}-\mathrm{E}$ \\
\hline ETH WIR-70 & $42.87 \mathrm{a}-\mathrm{e}$ & $46.87 \mathrm{ab}$ & $44.87 \mathrm{~A}$ & $56.53 \mathrm{bcd}$ & $67.11 \mathrm{a}$ & $61.82 \mathrm{~A}$ & $4.73 \mathrm{ab}$ & $4.00 \mathrm{a}-\mathrm{f}$ & $4.37 \mathrm{AB}$ \\
\hline Ortalama & $41.91 \mathrm{~A}$ & $40.47 \mathrm{~B}$ & & $56.93 \mathrm{~B}$ & $59.05 \mathrm{~A}$ & & $3.81 \mathrm{~B}$ & $4.19 \mathrm{~A}$ & \\
\hline Önemlilik düzeyi & \multicolumn{3}{|c|}{ Genotip $(\mathrm{G})^{* *}, \mathrm{Y}_{11}(\mathrm{Y})^{* *}, \mathrm{GxY}^{* *}$} & \multicolumn{3}{|c|}{$\mathrm{G}^{* *}, \mathrm{Y}^{* *}, \mathrm{GxY}^{* *}$} & \multicolumn{3}{|c|}{$\mathrm{G}^{* *}, \mathrm{Y}^{* *}, \mathrm{GxY}^{* *}$} \\
\hline DK $(\%)$ & \multicolumn{3}{|c|}{3.91} & \multicolumn{3}{|c|}{4.43} & \multicolumn{3}{|c|}{9.72} \\
\hline
\end{tabular}

${ }^{1}$ : Aynı grupta aynı harfle gösterilen ortalamalar arasındaki farklılık istatistiki açıdan önemli değildir, **: $\mathrm{p}<0.01$ hata sınırları içerisinde önemlidir, DK: Değişim katsayısı

\subsection{Ana Sap Uzunluğu}

Ana sap uzunluğu yönünden, genotipler ve yıllar arasında istatistiksel açıdan $\mathrm{p}<0.01$ düzeyinde önemli farklılıklar olduğu görülmüştür. İki yılın ortalamasına göre, en yüksek ana sap uzunluğu değeri ETH WIR-70 (61.82 cm) genotipinde belirlenmiştir. Ancak, ETH WIR-70 genotipine ait ana sap uzunluğu değeri ile IFLS 206, Sel 299, Sel 2273 ve Sel 440 genotipleri hariç diğer genotipler arasındaki farklılık istatistiksel açıdan önemsiz çıkmıştır (Tablo 3). Ana sap uzunluğu yönünden genotipler arasındaki bu farklılığa, genetik yapılarının sebep olduğu düşünülmektedir. Ana sap uzunluğu yönünden L. sativus genotipleri arasında önemli farklılıkların olduğu bazı araştırma sonuçlarında (Sayar ve ark., 2013; Seydoşoğlu ve ark., 2015) da rapor edilmiştir. 
Araştırmada en yüksek ana sap uzunluğu değeri genotiplerin ortalaması olarak $59.05 \mathrm{~cm}$ ile 2017 yılında ölçülmüştür (Tablo 3). Yıllar arasındaki bu değişkenlik, iklim özelliklerinin farklı olması ile açılanabilir. Genotip x yıl interaksiyonu incelendiğinde; en yüksek ana sap uzunluğu çalışmanın ikinci yılında ETH WIR-70 $(67.11 \mathrm{~cm})$, ilk yılında ise Sel $1837(63.27 \mathrm{~cm})$ genotipinde tespit edilmiştir. Benzer şekilde bazı genotipler her iki yılda da farklı performanslar göstermiştir. Bunun sonucunda genotip x yıl interaksiyonu istatistiksel açıdan $\mathrm{p}<0.01$ düzeyinde önemli çıkmıştır (Tablo 3).

Yaygın mürdümükte Türkiye'nin farklı ekolojilerinde yapılan araştırmalarda ana sap uzunluklarını; Şanlıurfa'da Bucak (1999) 46.37-114.95 cm, Konya'da Gündüz (2012) 26-70 cm, Diyarbakır'da Seydoşoğlu ve ark. (2015) 74.42-98.75 cm, Tekirdağ'da Tenikecier ve ark. (2017) $30.27-92.75$ cm, Elazığ'da Özdemir (2016) $23.67-31.53 \mathrm{~cm}$ ve Antalya'da Öten ve ark. (2017) 81.3-127.6 cm arasında değiştiğini tespit etmişlerdir. Türkiye'nin farklı bölgelerinde yapılan çalışmalarda görüldüğü gibi, ana sap uzunluğu çalışmaların kurulduğu yerin ekolojisinin değişmesine bağlı olarak farklılık gösterdiği söylenebilir.

\subsection{Ana Sap Sayısı}

İki yılın ortalama sonuçları incelendiğinde, ana sap sayısı yönünden yaygın mürdümük genotipleri arasındaki farklılık istatistiksel açıdan $\mathrm{p}<0.01$ düzeyinde önemli bulunmuştur. İki yılın ortalamasına göre, en yüksek ana sap sayısı istatistiksel olarak birinci grubu oluşturan Sel 668 (4.70 adet/bitki) ve Sel 1794 (4.70 adet/bitki) genotiplerinde belirlenmiştir. Ancak, adı geçen bu genotiplere ait ana sap sayısı değerleri ile IFLS 349, IFLS 257, IFLS 298 ve Gürbüz-2001 genotipleri hariç diğer genotipler arasındaki farklılık istatistiksel açıdan önemsiz çıkmıştır (Tablo 3). Yaygın mürdümük ile yapılan diğer çalışmalar gözden geçirildiğinde, farklı genotiplere ait ana sap sayısını; Bucak (1999) 3.57-10.23 adet/bitki, Kumar ve Dubey (2003) 4.6-8.6 adet/bitki, Tadesse ve Bekele (2003) 8.8-10.0 adet/bitki, Rybinski ve ark. (2008) 3.86-6.46 adet/bitki, Kökten ve Bakoğlu (2011) 4.30-5.47 adet/bitki, Gündüz (2012) 4-8 adet/bitki ve Özdemir (2016) 2.55-4.00 adet/bitki arasında değişim gösterdiğini bildirmişlerdir. Önceki çalışmalardan da anlaşılacağı üzere, ana sap sayısının oldukça değişken bir karakter olduğunu söylemek mümkündür. Literatürde bildirilen bu değerler ile çalışmamız bulguları arasındaki farklılıkların nedeni olarak, genotipik ve yetiştirilme şartlarının farklı olması gösterilebilir.

Ana sap sayısı yönünden yıllar arasındaki farklılık istatistiki açıdan $p<0.01$ düzeyinde önemli bulunmuş, en yüksek değerler araştırmanın ikinci yılında elde edilmiştir. Genotip x yıl interaksiyonu incelendiğinde, ilk yıl Sel 1794 (5.0 adet/bitki), ikinci yıl ise Sel 668 (5.0 adet/bitki) genotiplerinde en yüksek ana sap sayısı değerleri belirlenmiştir. Genotip x yıl interaksiyonu istatistiksel açıdan önemli $(\mathrm{p}<0.01)$ bulunmuştur (Tablo 3 ).

\subsection{Yeşil Ot Verimi}

Araştırmada incelenen yaygın mürdümük genotiplerinin yeşil ot verimlerine ait değerleri Tablo 4'te verilmiştir. İki yllın ortalamasına göre; en yüksek yeşil ot verimi $1890.4 \mathrm{~kg} / \mathrm{da}$ ile IFLS 257 genotipinde belirlenmiş olup, IFLS 257 genotipi ile IFLS 349, IFLS 298, GAP Mavisi, IFLS 968, Gürbüz-2001, Sel 666, Sel 668, Sel 681, Sel 702, Sel 706, Sel 2273, Sel 2329, Sel 421, Sel 1794 ve ETH WIR-70 genotiplerine ait yeşil ot verimi değerleri arasındaki farklılık istatistiki açıdan önemsiz bulunmuştur. Çalışmada, en düşük yeşil ot verimi ise $1348.1 \mathrm{~kg} / \mathrm{da}$ ile Sel 1837 genotipinde saptanmıştır. Genotipler arasındaki bu farklılık istatistiki açıdan $\mathrm{p}<0.01$ düzeyinde önemli bulunmuştur (Tablo 4).

Yaygın mürdümük genotipleri ile yürütülen araştırmalarda, araştırmamız bulgularında olduğu gibi yeşil ot verimi yönünden genotipler arasında istatistiksel açıdan önemli ve/veya çok önemli farklılıkların tespit edildiği ve yeşil ot veriminin genetik yapının etkisine bağlı olarak genotiplere göre önemli değişimler gösterdiği ifade edilmiştir. Türkiye'nin değiş̧ik ekolojilerinde farklı genotiplerle yapılan bu çalışmalar incelendiğinde yeşil ot veriminin; Van ekolojik koşullarında Andiç ve ark. (1996) 597.1-1452.5 kg/da, Isparta'da Balabanlı ve Kara (2003) 467.3-816.7 kg/da, Tokat koşullarında Karadağ ve İptaş (2007) 1000.0-1520.8 kg/da, Elazığ'da Kökten ve Bakoğlu (2011) 1482.3-1569.3 kg/da arasında değişim gösterdiğini rapor etmişlerdir. Araştırmamızda elde edilen bulguların literatürdeki bu bulgulardan yüksek olduğu görülmüştür. Bu durum, kullanılan genotipler ile iklim ve toprak şartlarının farklı olmasıyla açılanabilir. Diğer taraftan, yeşil ot verimi yönünden elde edilen bulgularımızın Seydoşoğlu ve ark. (2015)'nın (1379.5-3154.2 kg/da), Öten ve ark. (2017)'nın (813.3-2552.0 kg/da) ve Tenikecier ve ark. (2017)'nın (1954.5-2233.3 kg/da) bulgularıyla uyum içerisinde olduğu görülmüştür.

Genotip x y1l interaksiyonu incelendiğinde; ilk y1l $1697.8 \mathrm{~kg} / \mathrm{da}$ ile IFLS 257 genotipinden en yüksek yeşil ot verimi elde edilirken, ikinci y1l $2379.3 \mathrm{~kg} / \mathrm{da}$ ile Sel 681 genotipinden elde edilmiştir. Y1llar ve genotipler arasındaki bu farklılık nedeniyle genotip x yıl interaksiyonu istatistiki açıdan $p<0.01$ düzeyinde önemli bulunmuştur. Öte yandan araştırmada, genotiplerin ortalaması olarak en yüksek yeşil ot verimi 2017 yılında belirlenmiş ve istatistiki olarak birinci grubu oluşturmuştur. Yıllar arasındaki bu farklılık istatistiki açıdan $\mathrm{p}<0.01$ düzeyinde önemli bulunmuştur (Tablo 4). İkinci yıl, ilk yıla göre daha fazla yeşil ot verimi elde edilmesi, mürdümüğün vejetasyon dönemindeki toplam yağış miktarının (Tablo 1) ikinci yıl daha fazla olması ile açıklanabilir. 
Tablo 4. Yaygın Mürdümük Genotiplerinde Belirlenen Yeşil ve Kuru Ot Verimine Ait Değerlerl

\begin{tabular}{|c|c|c|c|c|c|c|}
\hline \multirow{2}{*}{ Genotipler } & \multicolumn{3}{|c|}{ Yeşil Ot Verimi (kg/da) } & \multicolumn{3}{|c|}{ Kuru Ot Verimi (kg/da) } \\
\hline & 2016 & 2017 & Ortalama & 2016 & 2017 & Ortalama \\
\hline IFLS 349 & 1247.4 1-m & $2109.6 \mathrm{abc}$ & $1678.5 \mathrm{~A}-\mathrm{F}$ & $311.3 \mathrm{j}-\mathrm{p}$ & $515.6 \mathrm{abc}$ & $413.4 \mathrm{~A}-\mathrm{E}$ \\
\hline IFLS 257 & $1697.8 \mathrm{c}-1$ & $2083.0 \mathrm{a}-\mathrm{d}$ & $1890.4 \mathrm{~A}$ & $390.6 \mathrm{c}-\mathrm{o}$ & $506.2 \mathrm{a}-\mathrm{d}$ & $448.4 \mathrm{~A}$ \\
\hline IFLS 298 & $1487.4 \mathrm{f}-\mathrm{m}$ & $1641.5 \mathrm{c}-\mathrm{j}$ & $1564.5 \mathrm{~A}-\mathrm{F}$ & $347.0 \mathrm{f}-\mathrm{p}$ & $410.0 \mathrm{c}-\mathrm{m}$ & $378.5 \mathrm{~A}-\mathrm{E}$ \\
\hline IFLS 206 & 1303.7 h-m & $1656.3 \mathrm{c}-\mathrm{j}$ & $1480.0 \mathrm{C}-\mathrm{F}$ & $306.5 \mathrm{k}-\mathrm{p}$ & $410.7 \mathrm{c}-\mathrm{m}$ & 358.6 B-E \\
\hline GAP Mavisi & $1389.6 \mathrm{~g}-\mathrm{m}$ & $1860.7 \mathrm{a}-\mathrm{g}$ & $1625.2 \mathrm{~A}-\mathrm{F}$ & 319.8 h-p & $462.7 \mathrm{a}-\mathrm{g}$ & 391.2 A-E \\
\hline IFLS 968 & $1537.8 \mathrm{e}-\mathrm{m}$ & $1872.6 \mathrm{a}-\mathrm{g}$ & $1705.2 \mathrm{~A}-\mathrm{E}$ & $353.3 \mathrm{f}-\mathrm{p}$ & $477.7 \mathrm{a}-\mathrm{f}$ & $415.5 \mathrm{~A}-\mathrm{E}$ \\
\hline Gürbüz-2001 & $1558.5 \mathrm{~d}-1$ & 2011.9 a-f & $1785.2 \mathrm{~A}-\mathrm{D}$ & $357.3 \mathrm{e}-\mathrm{p}$ & $499.4 \mathrm{a}-\mathrm{d}$ & 428.4 A-D \\
\hline Sel 666 & $1425.2 \mathrm{~g}-\mathrm{m}$ & 1804.4 b-h & $1614.8 \mathrm{~A}-\mathrm{F}$ & 326.8 h-p & $439.8 \mathrm{a}-\mathrm{k}$ & $383.3 \mathrm{~A}-\mathrm{E}$ \\
\hline Sel 668 & $1247.41-\mathrm{m}$ & $1893.3 \mathrm{a}-\mathrm{g}$ & $1570.4 \mathrm{~A}-\mathrm{F}$ & $281.6 \mathrm{~m}-\mathrm{p}$ & $497.3 \mathrm{a}-\mathrm{d}$ & $389.5 \mathrm{~A}-\mathrm{E}$ \\
\hline Sel 676 & $1105.2 \mathrm{klm}$ & $1807.4 \mathrm{~b}-\mathrm{h}$ & $1456.3 \mathrm{DEF}$ & 260.9 op & $441.7 \mathrm{a}-\mathrm{j}$ & $351.3 \mathrm{CDE}$ \\
\hline Sel 681 & $1250.41-\mathrm{m}$ & $2379.3 \mathrm{a}$ & $1814.8 \mathrm{ABC}$ & 280.8 m-p & $559.5 \mathrm{ab}$ & 420.2 A-D \\
\hline Sel 702 & $1386.7 \mathrm{~g}-\mathrm{m}$ & $1857.8 \mathrm{a}-\mathrm{g}$ & $1622.2 \mathrm{~A}-\mathrm{F}$ & $316.71-p$ & $436.8 \mathrm{~b}-1$ & 376.7 A-E \\
\hline Sel 706 & $1629.6 \mathrm{c}-\mathrm{k}$ & 2023.7 a-e & $1826.7 \mathrm{AB}$ & $377.7 \mathrm{~d}-\mathrm{o}$ & $491.0 \mathrm{a}-\mathrm{e}$ & 434.4 ABC \\
\hline Sel 299 & $1197.01-\mathrm{m}$ & $1685.9 \mathrm{c}-\mathrm{j}$ & $1441.5 \mathrm{EF}$ & $285.3 \mathrm{~m}-\mathrm{p}$ & $452.4 \mathrm{a}-\mathrm{h}$ & 368.9 A-E \\
\hline Sel 1837 & $1108.1 \mathrm{klm}$ & $1588.1 \mathrm{c}-\mathrm{k}$ & $1348.1 \mathrm{~F}$ & 258.8 op & 403.4 c-n & $331.1 \mathrm{E}$ \\
\hline Sel 2267 & $1045.9 \mathrm{~lm}$ & 1979.3 a-f & 1512.6 B-F & $239.8 p$ & 510.9 a-d & 375.3 A-E \\
\hline Sel 2273 & $1271.11-\mathrm{m}$ & $1872.6 \mathrm{a}-\mathrm{g}$ & $1571.9 \mathrm{~A}-\mathrm{F}$ & $315.51-p$ & 490.6 a-e & 403.1 A-E \\
\hline Sel 2329 & 1531.9 e-m & $1828.1 \mathrm{~b}-\mathrm{h}$ & $1680.0 \mathrm{~A}-\mathrm{F}$ & $377.3 \mathrm{~d}-\mathrm{o}$ & $498.5 \mathrm{a}-\mathrm{d}$ & $437.9 \mathrm{AB}$ \\
\hline Sel 385 & $1185.21-\mathrm{m}$ & $1659.3 \mathrm{c}-\mathrm{j}$ & $1422.2 \mathrm{EF}$ & 274.3 nop & 448.7 a-1 & $361.5 \mathrm{~B}-\mathrm{E}$ \\
\hline Sel 421 & $1229.61-\mathrm{m}$ & $1976.3 \mathrm{a}-\mathrm{f}$ & $1603.0 \mathrm{~A}-\mathrm{F}$ & $302.91-\mathrm{p}$ & $505.1 \mathrm{a}-\mathrm{d}$ & 404.0 A-E \\
\hline Sel 440 & $1028.1 \mathrm{~m}$ & $1848.9 \mathrm{~b}-\mathrm{g}$ & $1438.5 \mathrm{EF}$ & 261.4 op & 480.5 a-f & $371.0 \mathrm{~A}-\mathrm{E}$ \\
\hline Sel 1794 & $1365.9 \mathrm{~g}-\mathrm{m}$ & $1869.6 \mathrm{a}-\mathrm{g}$ & $1617.8 \mathrm{~A}-\mathrm{F}$ & 337.0 g-p & $463.6 \mathrm{a}-\mathrm{g}$ & $400.3 \mathrm{~A}-\mathrm{E}$ \\
\hline ETH-24 & $1161.5 \mathrm{j}-\mathrm{m}$ & $1632.6 \mathrm{c}-\mathrm{k}$ & $1397.0 \mathrm{EF}$ & 275.3 nop & $410.9 \mathrm{c}-\mathrm{m}$ & $343.1 \mathrm{DE}$ \\
\hline ETH WIR-70 & $1380.7 \mathrm{~g}-\mathrm{m}$ & $2302.2 \mathrm{ab}$ & $1841.5 \mathrm{AB}$ & $303.31-\mathrm{p}$ & $571.2 \mathrm{a}$ & 437.2 ABC \\
\hline Ortalama & $1323.8 \mathrm{~B}$ & $1885.2 \mathrm{~A}$ & & $310.9 \mathrm{~B}$ & $474.3 \mathrm{~A}$ & \\
\hline Önemlilik düzeyi & \multicolumn{3}{|c|}{$\mathrm{G}^{* *}, \mathrm{Y}^{* *}, \mathrm{GxY}^{* *}$} & \multicolumn{3}{|c|}{$\mathrm{G}^{* *}, \mathrm{Y}^{* *}, \mathrm{GxY}^{* *}$} \\
\hline DK $(\%)$ & \multicolumn{3}{|c|}{9.79} & \multicolumn{3}{|c|}{10.18} \\
\hline
\end{tabular}

': Aynı grupta aynı harfle gösterilen ortalamalar arasındaki farklılık istatistiki açıdan önemli değildir, **: p<0.01 hata sınırları içerisinde önemlidir, DK: Değişim katsayısı

\subsection{Kuru Ot Verimi}

Kuru ot verimleri açısından genotipler arasında istatistiksel olarak çok önemli $(\mathrm{p}<0.01)$ farklılıklar belirlenmiştir. İki y1lın ortalama verilerine göre; en yüksek kuru ot verimi $448.4 \mathrm{~kg} / \mathrm{da}$ ile IFLS 257 genotipinde belirlenmiş olup; IFLS 257 genotipi ile IFLS 206, Sel 676, Sel 1837, Sel 385 ve ETH-24 genotipleri hariç diğer genotiplerine ait kuru ot verimi değerleri arasındaki farklılık istatistiki açıdan önemsiz bulunmuştur. Çalışmada, en düşük kuru ot verimi ise $331.1 \mathrm{~kg} / \mathrm{da}$ ile Sel 1837 genotipinde saptanmıştır (Tablo 4). Yaygın mürdümük (L. sativus L.) genotipleri arasında kuru ot verimi yönünden farkll1ıkların olduğu birçok araştırma bulgularında da rapor edilmiştir (Abd E1-Moneim and Cocks, 1993; Balabanlı ve Kara, 2003; Karadağ ve ark., 2004; Sayar ve ark., 2013; Seydoşoğlu ve ark., 2015; Öten ve ark., 2017). Genotiplerin farklı genetik yapılarından dolayı yetiştirildiği ortamın iklim ve toprak şartlarına uyum yeteneklerinin farklı olmasının, genotipler arasındaki kuru ot verimi değerlerinin değişkenlik göstermesine neden olduğu düşünülmektedir.

Genotip x y1l interaksiyonu incelendiğinde; kuru ot veriminin yllar ve genotipler arasında $239.8 \mathrm{~kg} / \mathrm{da}$ (2016 yll, Sel 2267 genotipi) ile $571.2 \mathrm{~kg} / \mathrm{da}$ (2017 yılı, ETH WIR-70 genotipi) arasında değişim gösterdiği görülmektedir. Bu değişim istatistiksel açıdan $\mathrm{p}<0.01$ düzeyinde önemli bulunmuştur. Yıllar arasındaki farklılık da istatistiksel açıdan çok önemli $(p<0.01)$ bulunmuş, en yüksek kuru ot verimi genotiplerin ortalaması olarak araştırmanın ikinci yılında tespit edilmiştir (Tablo 4).

Çalışmada elde edilen kuru ot verimlerine ait bulgular; Çakmakçı ve Aydınoğlu (2002)'nun (311.9-493.6 kg/da), Öten ve ark. (2017)'nın (147.9-681.7 kg/da) ve Tenikecier ve ark. (2017)'nın (256.9-911.7 kg/da) çalışmalarıyla ile uyum içindeyken; Ahmadi ve ark. (2015)'nın (97.5-183.5 kg/da) ve Özdemir (2016)'in (86.8-265.8 kg/da) bulgularından yüksek bulunmuştur. Bu çalışmanın sonucu ile diğer çalışmaların arasındaki farklılıkların genotip ve çevresel faktörlerden kaynaklandığı düşünülmektedir.

\subsection{Bitkide Bakla Sayısı}

Bakla sayısı bakımından genotipler arasındaki farklılık istatistiki olarak $\mathrm{p}<0.01$ düzeyinde önemli bulunmuştur. Y1lların ortalamasına göre, en yüksek bitkide bakla sayısı değeri 17.7 adet/bitki ile Sel 1794 genotipinden elde edilmiş; bu genotip ile araştırmada incelenen IFLS 968, Sel 706, Sel 2267, Sel 2273, Sel 421 ve Sel 440 genotipleri arasindaki farkl1l1k istatistiki yönden önemsiz bulunmuştur. En düşük bakla sayısı ise 11.3 adet/bitki ile Sel 1837 genotipinden elde edilmiştir (Tablo 5).

Yaygın mürdümükte yapılan değişik çalışmalarda, bitkide bakla sayısını; Milczak ve ark. (2001) 17.9-24.0 adet, Gül ve ark. (2004) 21.9-27.9 adet, Rybinski ve ark. (2008) 20.3-60.3 adet, Kökten ve Bakoğlu (2011) 16.3-20.4 adet, Özdemir (2016) 6.0-16.0 adet ve 
Öten ve ark. (2017) 9.6-35.8 adet arasında değiştiğini rapor etmişlerdir. Bitkide bakla sayısı yönünden, araştırmamız bulguları ile literatürlerdeki bu bulgular arasındaki farklılığın, iklim ve genetik varyasyondan kaynaklandığı düşünülmektedir.

\subsection{Baklada Tane Sayısı}

Baklada tane sayıları yıllara ve genotiplere göre 1.9-3.2 adet arasında değişmiş olup, genotipler arasındaki farklılık istatistiksel açıdan çok önemli $(p<0.01)$ bulunmuştur. En yüksek baklada tane sayısı değeri yılların ortalaması olarak 3.1 adet ile ETH-24 genotipinde belirlenmiş olup; ETH-24 genotipi ile IFLS 349, IFLS 257, IFLS 206, Gürbüz-2001, Sel 666, Sel 668, Sel 681, Sel 299, Sel 2267, Sel 2273, Sel 2329, Sel 385, Sel 421 ve ETH WIR-70 genotiplerine ait baklada tane sayıs1 değerleri arasındaki farklılık istatistiki açıdan önemsiz bulunmuştur (Tablo 5). Baklada tane sayısı, genotip ve ekolojik koşullara göre değişiklik gösterdiği birçok araştırmacılar tarafından rapor edilmiştir (Şehirali, 1980; Bayram ve ark., 2004; Pekşen, 2005; Öten ve ark., 2017).

Farklı ekolojilerde yürütülen çalışmalarda, baklada tane sayısı değerinin Gedik (2007) 2.3-2.9 adet, Rybinski ve ark. (2008) 1.1-3.5 adet, Gündüz (2012) 2.3- 3.0 adet ve Seydoşoğlu ve ark. (2015) 3.0-3.7 adet arasında değiştiğini bildirmişlerdir.

\subsection{Bin Tane A ̆ğırlığı}

Bin tane ağırlıkları yönünden genotipler arasında istatistiksel açıdan $p<0.01$ düzeyinde önemli farklı1ıklar tespit edilmiştir. En yüksek bin tane ağırlığı Sel 1794 (125.87 g) genotipinde saptanmıştır. Bin tane ağırlığı yönünden Sel 1794 genotipi ile IFLS 968, Sel 2267, Sel 421 ve Sel 440 genotipleri arasındaki farklılık istatistiki açıdan önemsiz bulunmuştur. En düşük bin tane ağırlıklarına sahip genotip ise $79.36 \mathrm{~g}$ ile Sel 1837 olmuştur (Tablo 5).

Bin tane ağırlı̆ğ ile ilgili elde edilen sonuçlar; Bayram ve ark. (2004)'nın (89.9-182.1 g), Tavoletti ve ark. (2005)'nın (79.0-276.0 g), Gedik (2007)'in (85.3-154.0 g) ve Rybinski ve ark. (2008)'nın (91.0-492.0 g) bulgularıla uyumlu iken; Sabancı ve Özpınar (2000)'ın 58.0-68.0 g arasında elde ettiği değerlerden yüksek; Gül ve ark. (2004)'nın (124.4-144.9 g) ve Polignano ve ark. (2009)'nın (238-410 g) elde ettiği bulgulardan düşük bulunmuştur. Bu çalışmanın sonuçları ile diğer araştırmacıların bulguları arasındaki farklılıkların nedeni, kullanılan genotipler ya da yetiştirilme şartlarıyla ilgili olduğu düşünülmektedir.

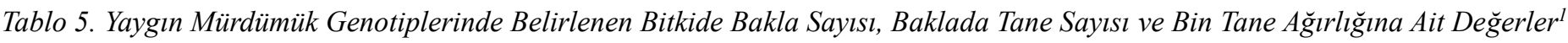

\begin{tabular}{|c|c|c|c|c|c|c|c|c|c|}
\hline \multirow{2}{*}{ Genotipler } & \multicolumn{3}{|c|}{ Bitkide Bakla Sayısı (adet) } & \multicolumn{3}{|c|}{ Baklada Tane Sayısı (adet) } & \multicolumn{3}{|c|}{ Bin Tane Ağırlığı (g) } \\
\hline & 2016 & 2017 & Ortalama & 2016 & 2017 & Ortalama & 2016 & 2017 & Ortalama \\
\hline IFLS 349 & 13.7 & 13.4 & 13.6 EFG & 2.5 & 2.6 & $2.6 \mathrm{~A}-\mathrm{E}$ & 90.95 & 92.59 & 91.77 F-I \\
\hline IFLS 257 & 14.3 & 14.3 & 14.3 C-F & 2.4 & 2.5 & $2.5 \mathrm{~A}-\mathrm{E}$ & 95.24 & 94.47 & $94.86 \mathrm{EFG}$ \\
\hline IFLS 298 & 14.1 & 14.0 & 14.0 DEF & 2.5 & 2.3 & 2.4 B-E & 86.97 & 87.48 & $87.22 \mathrm{GHI}$ \\
\hline IFLS 206 & 12.6 & 12.5 & $12.5 \mathrm{FG}$ & 2.7 & 2.8 & 2.7 A-D & 81.77 & 81.26 & $81.51 \mathrm{HI}$ \\
\hline GAP Mavisi & 15.1 & 15.2 & 15.2 B-E & 2.5 & 2.2 & $2.4 \mathrm{~B}-\mathrm{E}$ & 100.41 & 100.09 & 100.25 DEF \\
\hline IFLS 968 & 15.8 & 16.1 & 15.9 A-D & 2.4 & 2.5 & 2.4 B-E & 115.67 & 115.66 & $115.67 \mathrm{ABC}$ \\
\hline Gürbüz-2001 & 15.1 & 15.3 & 15.2 B-E & 2.8 & 2.7 & 2.7 A-D & 89.36 & 90.52 & 89.94 F-I \\
\hline Sel 666 & 13.5 & 15.1 & 14.3 C-F & 2.5 & 2.6 & $2.5 \mathrm{~A}-\mathrm{E}$ & 104.67 & 106.02 & 105.35 CDE \\
\hline Sel 668 & 14.1 & 13.5 & 13.8 DEF & 2.6 & 2.4 & $2.5 \mathrm{~A}-\mathrm{E}$ & 86.95 & 87.86 & $87.40 \mathrm{GHI}$ \\
\hline Sel 676 & 14.3 & 14.2 & 14.3 C-F & 2.5 & 2.3 & 2.4 B-E & 88.73 & 89.38 & 89.06 F-I \\
\hline Sel 681 & 13.1 & 15.0 & 14.1 DEF & 2.5 & 2.7 & 2.6 A-E & 107.89 & 109.33 & 108.61 BCD \\
\hline Sel 702 & 15.5 & 15.1 & 15.3 B-E & 2.4 & 2.1 & $2.3 \mathrm{CDE}$ & 112.39 & 113.36 & $112.87 \mathrm{BCD}$ \\
\hline Sel 706 & 14.7 & 16.1 & 15.4 A-E & 2.7 & 2.2 & 2.4 B-E & 112.35 & 113.86 & $113.10 \mathrm{BC}$ \\
\hline Sel 299 & 13.1 & 12.6 & $12.8 \mathrm{FG}$ & 2.7 & 3.2 & $2.9 \mathrm{AB}$ & 87.46 & 91.93 & 89.70 F-I \\
\hline Sel 1837 & 11.5 & 11.1 & $11.3 \mathrm{G}$ & 2.2 & 2.1 & $2.1 \mathrm{DE}$ & 78.37 & 80.35 & $79.36 \mathrm{I}$ \\
\hline Sel 2267 & 15.5 & 17.2 & 16.4 ABC & 2.7 & 3.1 & $2.9 \mathrm{ABC}$ & 117.36 & 118.42 & $117.89 \mathrm{ABC}$ \\
\hline Sel 2273 & 15.2 & 15.8 & 15.5 A-E & 2.6 & 2.5 & $2.6 \mathrm{~A}-\mathrm{E}$ & 108.67 & 109.22 & 108.94 BCD \\
\hline Sel 2329 & 14.1 & 14.0 & 14.1 DEF & 2.9 & 2.5 & 2.7 A-D & 91.47 & 92.78 & $92.12 \mathrm{FGH}$ \\
\hline Sel 385 & 13.7 & 13.8 & $13.8 \mathrm{DEF}$ & 3.0 & 3.0 & $3.0 \mathrm{AB}$ & 86.67 & 89.70 & 88.18 F-I \\
\hline Sel 421 & 15.7 & 17.7 & $16.7 \mathrm{AB}$ & 2.7 & 2.8 & 2.8 A-D & 117.84 & 118.85 & $118.34 \mathrm{AB}$ \\
\hline Sel 440 & 16.2 & 15.4 & 15.8 A-E & 2.1 & 1.9 & $2.0 \mathrm{E}$ & 115.85 & 115.53 & $115.69 \mathrm{ABC}$ \\
\hline Sel 1794 & 17.1 & 18.2 & $17.7 \mathrm{~A}$ & 2.4 & 2.2 & $2.3 \mathrm{~B}-\mathrm{E}$ & 124.96 & 126.78 & $125.87 \mathrm{~A}$ \\
\hline ETH-24 & 13.4 & 14.7 & 14.0 DEF & 3.0 & 3.2 & $3.1 \mathrm{~A}$ & 107.02 & 106.89 & 106.95 B-E \\
\hline ETH WIR-70 & 13.4 & 13.8 & 13.6 EFG & 2.6 & 3.1 & $2.8 \mathrm{ABC}$ & 106.15 & 106.91 & 106.53 B-E \\
\hline Ortalama & 14.4 & 14.8 & 14.6 & 2.6 & 2.6 & 2.6 & 101.63 & 100.63 & 101.13 \\
\hline Önemlilik düzeyi & \multicolumn{3}{|c|}{$\mathrm{G}^{* *}$} & \multicolumn{3}{|c|}{$\mathrm{G}^{* *}$} & \multicolumn{3}{|c|}{$\mathrm{G}^{* *}$} \\
\hline DK (\%) & \multicolumn{3}{|c|}{7.29} & \multicolumn{3}{|c|}{11.7} & \multicolumn{3}{|c|}{5.78} \\
\hline
\end{tabular}

\subsection{Tohum Verimi}

Yaygın mürdümük genotiplerinin tohum verimi değerlerine ait ortalamalarla yapılan varyans analizi sonucunda, genotipler arasında istatistiksel açıdan çok önemli $(\mathrm{p}<0.01)$ farklılıklar belirlenmiştir. Yılların ortalamasına göre, en yüksek tohum verimi $194.5 \mathrm{~kg} / \mathrm{da}$ ile e-ISSN: 2148-2683 
Sel 1794 genotipinde belirlenmiş olup; Sel 1794 genotipi ile IFLS 968, Sel 702, Sel 706, Sel 2267, Sel 2273, Sel 421 ve Sel 440 genotiplerine ait tohum verimi değerleri arasında farklı1ık istatistiki açıdan önemsiz bulunmuştur. En düşük tohum verimi değeri ise $101.3 \mathrm{~kg} / \mathrm{da}$ ile Sel 1837 genotipinde tespit edilmiştir (Tablo 6). Yaygın mürdümük (L. sativus L.)'te tohum veriminin genotipler arasında önemli değişimler gösterdiği ve tohum veriminin $60.14-269.83 \mathrm{~kg} / \mathrm{da}$ arasında değiştiği birçok araş̧ırma bulgularında da rapor edilmiştir (Bucak, 1999; Sabancı ve Özpınar, 2000; Bayram ve ark., 2004; Gül ve ark., 2004; Kökten ve Bakoğlu, 2011; Karadağ ve ark., 2012; Seydoşoğlu ve ark., 2015). Tohum verimi yönünden genotipler arasındaki farkl1lığa, kullanılan materyallerin genotipik özelliklerin ve ekolojik faktörlerin etkili olduğu düşünülmektedir.

Genotip x yıl interaksiyonu incelendiğinde; tohum veriminin genotipler ve yıllar arasında önemli değişimler gösterdiği, iklim ve toprak özelliklerinin farklılı̆̆ına bağlı olarak bazı genotiplerin (Örneğin, Sel 1794, IFLS 968, IFLS 257, Gürbüz-2001) yıllar itibariyle farklı performans sergilediği görülmüştür. Bu nedenle genotip x yıl interaksiyonu istatistiksel açıdan $p<0.01$ düzeyinde önemli çıkmıştır (Tablo 6).

\subsection{Biyolojik Verim}

Biyolojik verim yönünden genotipler arasında istatistiksel açıdan çok önemli $(\mathrm{p}<0.01)$ farklılıklar belirlenmiştir. En yüksek biyolojik verim değeri $707.5 \mathrm{~kg} / \mathrm{da}$ ile Sel 2329 genotipinde belirlenmiş olup, Sel 2329 genotipi ile IFLS 257, IFLS 298, Gürbüz-2001, Sel 706 ve ETH WIR-70 genotiplerine ait biyolojik verim değerleri arasında farklılık istatistiki açıdan önemsiz bulunmuştur. En düşük biyolojik verim değeri $444.8 \mathrm{~kg} / \mathrm{da}$ ile IFLS 349 genotipinde tespit edilmiştir (Tablo 6).

Farklı ekolojilerde yapılan çalışmalarda biyolojik verimin, örneğin; İzmir-Menemen koşullarında 781-1188 kg/da (Sabancı ve Özpınar, 2000), Bursa ekolojik koşullarında 166.7-791.7 kg/da (Türk ve ark., 2007), Tokat-Kazova koşullarında 565.8-693.7 kg/da (Karadağ ve ark., 2012), İran ekolojisinde 350.4-584.2 kg/da (Ahmadi ve ark., 2015), Diyarbakır koşullarında 528.2-847.1 kg/da (Sayar ve Han, 2015) ve Elazığ ekolojik koşullarında 146.33-278.90 kg/da (Özdemir, 2016) arasında değişim gösterdiği rapor edilmiştir. Araştırmamız bulgularının literatürdeki bazı verilerle uyumlu, bazı sonuçlardan ise farklılık gösterdiği görülmektedir. Farklılığın nedeni olarak, kullanılan genotipler ya da denemelerin kurulu olduğu bölgenin ekolojik şartları ile ilgili olduğu düşünülmektedir.

Tablo 6. Yaygın Mürdümük Genotiplerinde Belirlenen Tohum Verimi, Biyolojik Verim ve Hasat İndeksine Ait Değerler ${ }^{1}$

\begin{tabular}{|c|c|c|c|c|c|c|c|c|c|}
\hline \multirow{2}{*}{ Genotipler } & \multicolumn{3}{|c|}{ Tohum Verimi (kg/da) } & \multicolumn{3}{|c|}{ Bivolojik Verim (kg/da) } & \multicolumn{3}{|c|}{ Hasat İndeksi (\%) } \\
\hline & 2016 & 2017 & Ortalama & 2016 & 2017 & Ortalama & 2016 & 2017 & Ortalama \\
\hline IFLS 349 & $122.7 \mathrm{e}-\mathrm{j}$ & $124.4 \mathrm{e}-\mathrm{j}$ & $123.6 \mathrm{~F}-\mathrm{I}$ & 440.0 & 449.7 & $444.8 \mathrm{~J}$ & 27.9 a-1 & $30.2 \mathrm{a}-\mathrm{j}$ & $29.1 \mathrm{~B}-\mathrm{F}$ \\
\hline IFLS 257 & $159.7 \mathrm{a}-1$ & $143.7 \mathrm{~b}-\mathrm{j}$ & $151.7 \mathrm{~B}-\mathrm{F}$ & 618.6 & 631.1 & 624.9 A-E & $26.0 \mathrm{~d}-\mathrm{n}$ & $22.8 \mathrm{f}-\mathrm{n}$ & $24.4 \mathrm{C}-\mathrm{H}$ \\
\hline IFLS 298 & $155.6 \mathrm{~b}-1$ & $128.9 \mathrm{~d}-\mathrm{j}$ & $142.2 \mathrm{C}-\mathrm{H}$ & 693.3 & 695.0 & $694.2 \mathrm{AB}$ & 23.7 e-n & $19.7 \mathrm{k}-\mathrm{n}$ & $21.7 \mathrm{GH}$ \\
\hline IFLS 206 & $120.0 \mathrm{f}-\mathrm{j}$ & $106.7 \mathrm{ij}$ & $113.3 \mathrm{HI}$ & 592.6 & 595.1 & $593.9 \mathrm{C}-\mathrm{F}$ & $20.3 \mathrm{k}-\mathrm{n}$ & $18.0 \mathrm{mn}$ & $19.1 \mathrm{H}$ \\
\hline GAP Mavisi & $151.6 \mathrm{~b}-1$ & $151.1 \mathrm{~b}-1$ & $151.3 \mathrm{~B}-\mathrm{F}$ & 639.4 & 638.0 & 638.7 A-D & $25.1 \mathrm{~d}-\mathrm{n}$ & 23.8 e-n & $24.5 \mathrm{C}-\mathrm{H}$ \\
\hline IFLS 968 & $179.7 \mathrm{a}-\mathrm{d}$ & $171.9 \mathrm{a}-\mathrm{f}$ & $175.8 \mathrm{ABC}$ & 545.6 & 540.6 & $543.1 \mathrm{E}-\mathrm{I}$ & $37.0 \mathrm{a}$ & $31.8 \mathrm{a}-\mathrm{f}$ & $34.4 \mathrm{AB}$ \\
\hline Gürbüz-2001 & $168.9 \mathrm{a}-\mathrm{f}$ & $139.6 c-j$ & $154.2 \mathrm{~B}-\mathrm{F}$ & 669.0 & 671.5 & $670.2 \mathrm{ABC}$ & $26.9 \mathrm{~b}-\mathrm{n}$ & $20.8 \mathrm{j}-\mathrm{n}$ & $23.9 \mathrm{D}-\mathrm{H}$ \\
\hline Sel 666 & $149.3 \mathrm{~b}-1$ & $154.1 \mathrm{~b}-1$ & 151.7 B-F & 601.9 & 605.2 & $603.5 \mathrm{C}-\mathrm{F}$ & $26.2 \mathrm{~d}-\mathrm{n}$ & 26.2 d-n & $26.2 \mathrm{C}-\mathrm{G}$ \\
\hline Sel 668 & $147.0 \mathrm{~b}-\mathrm{j}$ & $127.4 \mathrm{~d}-\mathrm{j}$ & 137.2 D-H & 586.7 & 592.2 & $589.4 \mathrm{C}-\mathrm{G}$ & $25.1 \mathrm{~d}-\mathrm{n}$ & $21.5 \mathrm{~h}-\mathrm{n}$ & $23.3 \mathrm{E}-\mathrm{H}$ \\
\hline Sel 676 & $131.3 \mathrm{c}-\mathrm{j}$ & $130.4 \mathrm{c}-\mathrm{j}$ & $130.8 \mathrm{E}-\mathrm{I}$ & 503.7 & 502.6 & $503.2 \mathrm{G}-\mathrm{J}$ & $26.1 \mathrm{~d}-\mathrm{n}$ & $25.9 \mathrm{~d}-\mathrm{n}$ & $26.0 \mathrm{C}-\mathrm{G}$ \\
\hline Sel 681 & $119.3 \mathrm{f}-\mathrm{j}$ & $157.0 \mathrm{~b}-1$ & $138.1 \mathrm{D}-\mathrm{H}$ & 471.7 & 473.5 & $472.6 \mathrm{IJ}$ & $25.3 \mathrm{~d}-\mathrm{n}$ & $33.2 \mathrm{a}-\mathrm{e}$ & 29.3 B-E \\
\hline Sel 702 & $172.3 \mathrm{a}-\mathrm{f}$ & 160.0 a-h & 166.1 A-D & 474.1 & 474.5 & $474.3 \mathrm{IJ}$ & $36.4 \mathrm{abc}$ & $36.5 \mathrm{ab}$ & $36.4 \mathrm{~A}$ \\
\hline Sel 706 & $162.1 \mathrm{a}-\mathrm{g}$ & $171.9 \mathrm{a}-\mathrm{f}$ & 167.0 A-D & 624.7 & 625.8 & 625.3 A-E & $26.0 \mathrm{~d}-\mathrm{n}$ & $27.5 \mathrm{a}-\mathrm{m}$ & $26.7 \mathrm{C}-\mathrm{G}$ \\
\hline Sel 299 & $122.5 \mathrm{e}-\mathrm{j}$ & $109.6 \mathrm{~g}-\mathrm{j}$ & $116.1 \mathrm{G}-\mathrm{I}$ & 615.4 & 619.7 & 617.5 B-F & $20.8 \mathrm{j}-\mathrm{n}$ & $17.7 \mathrm{n}$ & $19.2 \mathrm{H}$ \\
\hline Sel 1837 & $108.1 \mathrm{~h} 1 \mathrm{j}$ & $94.5 \mathrm{j}$ & $101.3 \mathrm{I}$ & 494.8 & 501.8 & $498.3 \mathrm{HIJ}$ & $24.9 \mathrm{~d}-\mathrm{n}$ & 18.9 k-n & $21.9 \mathrm{GH}$ \\
\hline Sel 2267 & $140.3 c-j$ & $182.2 \mathrm{a}-\mathrm{c}$ & 161.3 A-E & 535.2 & 538.2 & 536.7 F-I & $26.2 \mathrm{~d}-\mathrm{n}$ & $33.9 \mathrm{a}-\mathrm{d}$ & $30.1 \mathrm{BC}$ \\
\hline Sel 2273 & $174.2 \mathrm{a}-\mathrm{e}$ & 174.8 a-e & 174.5 ABC & 579.3 & 574.7 & $577.0 \mathrm{D}-\mathrm{H}$ & $30.8 \mathrm{a}-1$ & $26.8 \mathrm{c}-\mathrm{n}$ & 28.8 B-F \\
\hline Sel 2329 & $129.2 \mathrm{c}-\mathrm{j}$ & $128.1 \mathrm{~d}-\mathrm{j}$ & 128.7 E-I & 702.2 & 712.8 & $707.5 \mathrm{~A}$ & $18.6 \mathrm{lmn}$ & $18.0 \mathrm{mn}$ & $18.3 \mathrm{H}$ \\
\hline Sel 385 & $120.7 \mathrm{f}-\mathrm{j}$ & $122.8 \mathrm{e}-\mathrm{j}$ & 121.8 F-I & 565.1 & 562.7 & $563.9 \mathrm{D}-\mathrm{H}$ & $21.41-\mathrm{n}$ & 21.8 h-n & $21.6 \mathrm{GH}$ \\
\hline Sel 421 & $164.6 \mathrm{a}-\mathrm{f}$ & $195.6 \mathrm{ab}$ & $180.1 \mathrm{AB}$ & 589.6 & 589.9 & $589.7 \mathrm{C}-\mathrm{G}$ & 27.9 a-1 & $33.2 \mathrm{a}-\mathrm{e}$ & $30.5 \mathrm{ABC}$ \\
\hline Sel 440 & $149.2 \mathrm{~b}-1$ & 171.9 a-f & $160.5 \mathrm{~A}-\mathrm{E}$ & 546.0 & 546.0 & 546.0 E-I & $28.4 \mathrm{a}-\mathrm{k}$ & $31.5 \mathrm{a}-\mathrm{g}$ & $29.9 \mathrm{BCD}$ \\
\hline Sel 1794 & $178.7 \mathrm{a}-\mathrm{d}$ & $210.4 \mathrm{a}$ & $194.5 \mathrm{~A}$ & 580.7 & 584.1 & $582.4 \mathrm{D}-\mathrm{H}$ & $31.0 \mathrm{a}-\mathrm{h}$ & $36.0 \mathrm{abc}$ & $33.5 \mathrm{AB}$ \\
\hline ETH-24 & $141.9 \mathrm{c}-\mathrm{j}$ & $157.0 \mathrm{~b}-1$ & 149.5 B-G & 497.8 & 508.8 & 503.3 G-J & $28.2 \mathrm{a}-\mathrm{k}$ & $31.1 \mathrm{a}-\mathrm{h}$ & $29.6 \mathrm{BCD}$ \\
\hline ETH WIR-70 & $131.3 \mathrm{c}-\mathrm{j}$ & $154.1 \mathrm{~b}-1$ & $142.7 \mathrm{C}-\mathrm{H}$ & 604.4 & 637.6 & $621.0 \mathrm{~A}-\mathrm{F}$ & $22.0 \mathrm{~g}-\mathrm{n}$ & $24.2 \mathrm{e}-\mathrm{n}$ & $23.1 \mathrm{FGH}$ \\
\hline Ortalama & 148.7 & 145.8 & 147.3 & 578.0 & 573.8 & 575.9 & 26.3 & 26.3 & 26.3 \\
\hline Önemlilik düzeyi & \multicolumn{3}{|c|}{$\mathrm{G}^{* *}, \mathrm{GxY}^{* *}$} & \multicolumn{3}{|c|}{$\mathrm{G}^{* *}$} & \multicolumn{3}{|c|}{$\mathrm{G}^{* *}, \mathrm{GxY}^{* *}$} \\
\hline DK (\%) & \multicolumn{3}{|c|}{10.75} & \multicolumn{3}{|c|}{6.96} & \multicolumn{3}{|c|}{10.83} \\
\hline
\end{tabular}

${ }^{1}$ : Aynı grupta aynı harfle gösterilen ortalamalar arasındaki farklılık istatistiki açıdan önemli değildir, **: p<0.01 hata sınırları içerisinde önemlidir, DK: Değişim katsayısı

\subsection{Hasat İndeksi}

Farklı yaygın mürdümük genotiplerinde tespit edilen hasat indeksi (HI) değerleri ile yapılan istatistiki analizler sonucunda, hasat indeksi yönünden genotipler arasında istatistiksel açıdan çok önemli $(\mathrm{p}<0.01)$ farklılıklar belirlenmiştir. İki yılın ortalama verilerine 
göre en yüksek Hİ \% 36.4 ile Sel 702 genotipinde belirlenmiştir. Sel 702 genotipi ile IFLS 968, Sel 421 ve Sel 1794 genotiplerinin HI arasındaki farklılık istatistiki açıdan önemsiz bulunmuştur. En düşük Hİ ise \% 18.3 ile Sel 2329 genotipinde saptanmıştır (Tablo 6).

Hasat indeksi yönünden elde edilen bulgular; Gül ve ark. (2004)'nın (\% 26-44), Türk ve ark. (2007)'nın (\% 5-82), Karadağ ve ark. (2012)'nın (\% 27.66-31.70), Ahmadi ve ark. (2015)'nın (\% 17.84-39.19), Sayar ve Han (2015)'ın (\% 32.0-40.87) ve Özdemir (2016)'in (\% 27.27-40.87) bulguları ile benzer gösterdiği söylenebilir.

Araştırmada, genotip x yıl interaksiyonu istatistiksel açıdan çok önemli $(\mathrm{p}<0.01)$ bulunmuştur. Genotiplere ve yıllara göre, en yüksek Hİ \% 37.0 ile araştırmanın birinci yılında, en düşük Hİ ise \% 17.7 ile çalışmanın ikinci yılında tespit edilmiştir (Tablo 6).

\section{Sonuç}

Siirt ili yarı kurak iklim koşullarında bazı yaygın mürdümük (L. sativus L.) genotiplerini tescilli çeşitlerle kıyaslamak suretiyle verim özelliklerinin belirlendiği bu çalışmada, incelenen genotipler içerisinde ümitvar olanlar bulunmaktadır. İki yıl süreyle yürütülen bu araştırma sonuçlarına göre; doğal bitki boyu, ana sap uzunluğu, ana sap sayısı gibi verime etkili parametreler, yeşil ot verimi ve kuru ot verimi değerleri ile birlikte değerlendirildiğinde, en yüksek ve/veya yüksek değerler gösteren grupta yer almalarından dolayı "ETH WIR-70" ve "IFLS 257" genotiplerinin öne çıktı̆̆ını söylemek mümkündür. Buna ek olarak; IFLS 298, IFLS 968, Sel 666, Sel 668, Sel 681, Sel 702, Sel 706, Sel 2273, Sel 2329, Sel 421 ve Sel 1794 genotipleri ot verimi bakımından tescilli çeşit olan Gürbüz-2001 ve GAP Mavisi çeşitleri ile benzer performanslar göstermesi sebebiyle, ümitvar genotipler olarak dikkati çekmiş̧ir.

Tohum üretimi amacıyla öne çıkan genotip "Sel 1794" genotipi olmuştur. Bu genotip, bitkide bakla sayısı ve bin tane ağırlığı gibi tohum verimine doğrudan etkili olan özellikler yönünden en üstün grupta yer almış ve tohum verimi bakımından da en verimli genotip olarak ortaya çıkmıştır. Araştırmada ayrıca, IFLS 968, Sel 702, Sel 706, Sel 2273, Sel 421 ve Sel 440 genotipleri tohum verimi yönünden tescilli çeşitlerden daha yüksek değerler göstermiş ve bu yönüyle de tohumluk için önemli sslah materyalleri olabileceği düşünülmektedir.

Yaygın mürdümük bitkisinin Siirt koşullarında yazlık olarak başarılı bir şekilde yetiştiriciliğinin yapılabileceği görülmüştür. Araştırma sonucunda öne çıkan ve ümitvar olan genotiplerin tarla denemelerinin devam ettirilmesinin uygun olacağ ve yapılacak çalışmalar sonucunda bölgeye uygun tescilli çeşitler geliştirebileceği ön görülmektedir. Böylece, Güneydoğu Anadolu Bölgesi’nde üretimi yaygın olmayan mürdümük bitkisinin bölge tarımına kazandırılmasına ve geniş alanlarda üretiminin yapılmasına katkı sağlanacağı düşünülmektedir.

\section{Teşekkür}

$\mathrm{Bu}$ çalışmanın ot verimi ve ilgili parametrelerine ait ilk yıl verileri, 21-22 Haziran 2018 tarihlerinde Gaziantep'te düzenlenen UMTEB-III. Uluslararası Mesleki ve Teknik Bilimler Kongresi'nde sözlü bildiri olarak sunulmuş olup, adı geçen kongre bildiriler kitabında özet metni yayınlanmıştır.

\section{Kaynakça}

Abd E1-Moneim, A. M., \& Cocks, P. S. (1993). Adaptation and yield stability of selected lines of Lathyrus spp. under rainfed conditions in West Asia. Euphytica, 66, 89-97.

Açıkgöz, N., \& Açıkgöz, N. (2001). Tarımsal araştırmaların istatistiki değerlendirilmesinde yapılan bazı hatalar: I. Tek faktörlü denemeler. Anadolu, 11(1), 135-147.

Ahmadi, J., Vaezi, B., \& Pour-Aboughadareh, A. (2015). Assessment of heritability and relationships among agronomic characters in grass pea (Lathyrus sativus L.) under rainfed conditions. Biharean Biologist, 9(1), 29-34.

Allkin, R., MacFarlane, T. D., White, R. J., Bisby, F. A., \& Adey, M. E. (1985). The Geographical Distribution of Lathyrus: Issue 1. Vicieae Database Project Publication No. 6, University of Southampton.

Andiç, C., Akdeniz, H., Yılmaz, İ., \& Terzioğlu, Ö. (1996). Van kıraç şartlarında adi mürdümük hatlarının (Lathyrus sativus L.) ot verimi üzerinde bir araştırma. Türkiye 3. Çayır, Mer'a ve Yem Bitkileri Kongresi, Erzurum.

Anonim. (2017). Meteoroloji Genel Müdürlüğü, Siirt İli İklim Verileri. https://www.mgm.gov.tr/veridegerlendirme/il-ve-ilceleristatistik.aspx?k=A\&m=SIIRT, Erişim tarihi: 28.11.2019.

Anonim. (2019). Baklagil Yem Bitkileri Tarımsal Değerleri Ölçme Denemeleri Teknik Talimatı. T.C. Tarım ve Orman Bakanlığı Bitkisel Üretim Genel Müdürlüğü, Ankara.

Balabanlı, C., \& Kara, B. (2003). Mürdümük hatlarının (Lathyrus sativus L.) Isparta koşullarında bazı agronomik özellikleri ile verim potansiyellerinin belirlenmesi. Tarla Bitkileri Merkez Araştırma Enstitüsü Dergisi, 12(1-2), 57-63.

Başaran, U., Acar, Z., Önal Aşcı, Ö., Mut, H., \& Ayan, İ. (2007). Mürdümük (Lathyrus sp.) türlerinin önemi, tarımda kullanım olanakları ve zararlı madde içerikleri. Ondokuz Mayıs Üniversitesi Ziraat Fakültesi Dergisi, 22(1), 139-148.

Bayram, G., Türk, M., Budaklı, E., \& Çelik, N. (2004). Bursa ekolojik koşullarında yetiştirilen yaygın mürdümük (Lathyrus sativus L.) hatlarının verim ve adaptasyonu üzerinde bir araştırma. Uludağ Üniversitesi Ziraat Fakültesi Dergisi, 18(2), 73-84.

Bucak, B. (1999). Harran Ovası koşullarında kışlık olarak yetiştirilen yerel mürdümük (Lathyrus ssp.) hatlarında botanik ve tarımsal yönlerinin belirlenmesi üzerinde araştırmalar. (Doktora tezi), Harran Üniversitesi, Fen Bilimleri Enstitüsü, Şanlıurfa, Türkiye.

Bucak, B. (2009). Kıraç koşullarında mürdümük (Lathyrus spp.) hatlarının tohum veriminin belirlenmesi. Harran Üniversitesi Ziraat Fakültesi Dergisi, 13(4), 57-65. 
Çakmakçı, S., \& Aydınoğlu, B. (2002). Akdeniz sahil kuşağında mürdümük (Lathyrus sativus L.) bitkisinde farklı sıra arası ve gübre dozlarının ot verimine etkisi. Akdeniz Üniversitesi Ziraat Fakültesi Dergisi, 15(1), 95-99.

Firıncıoğlu, H. K., Ünal, S., \& Özpınar, H. (2004). Grass pea (Lathyrus sativus L.) as a feed crop in mixed farming systems in Turkey. Journal of Field Crops Central Research Institute, 13(1-2), 29-36.

Gedik, A. (2007). Bazı müdümük (Lathyrus sativus L.) varyete, hat ve çeşitleri arasındaki morfolojik, tarımsal ve moleküler farklılıkların saptanması üzerine bir araştırma. (Yüksek lisans tezi), Çukurova Üniversitesi, Fen Bilimleri Enstitüsü, Adana, Türkiye.

Grela, E. R., Rybiński, W., Matras, J., \& Sobolewska, S. (2012). Variability of phenotypic and morphological characteristics of some Lathyrus sativus L. and Lathyrus cicera L. accessions and nutritional traits of their seeds. Genetic Resources and Crop Evolution, 59(8), 1687-1703.

Gül, D., Sümerli, M., \& Yılmaz, Y. (2004). Diyarbakır koşullarında bazı mürdümük (Lathyrus sativus L.) hatlarının verim ve verim unsurlarının belirlenmesi. Tarım Bilimleri Dergisi, 10(4), 416-421.

Gündüz, G. M. (2012). Köy populasyonu yaygın mürdümük (Lathyrus sativus L.) çeşitlerinin tohum verimi ve bazı bitkisel özellikleri. (Yüksek lisans tezi), Selçuk Üniversitesi, Fen Bilimleri Enstitüsü, Konya, Türkiye.

Hanbury, C. D., White, C. L., Mullan, B. P., \& Siddique, K. H. M. (2000). A review of the potential of Lathyrus sativus L. and L. cicera L. grain for use as animal feed. Animal Feed Science and Technology, 87, 1-27.

Karadağ, Y., \& İptaş, S. (2007, Haziran). Tokat ekolojik koşullarında bazı mürdümük (Lathyrus sativus L.) hat ve varyetelerinin agronomik potansiyelleri üzerine bir araştırma. Türkiye VII. Tarla Bitkileri Kongresi, Erzurum.

Karadağ, Y., İptaş, S., \& Yavuz, M. (2004). Agronomic potential of grasspea (Lathyrus sativus L.) under rainfed condition in semi-arid regions of Turkey. Asian Journal of Plant Sciences, 3(2), 151-155.

Karadağ, Y., Özkurt, M., Akbay, S., \& Kır, H. (2012). Tokat-Kazova ekolojik koşullarında bazı mürdümük (Lathyrus sativus L.) hatlarının verim ve verim özelliklerinin belirlenmesi. Tarım Bilimleri Araştırma Dergisi, 5(2), 11-13.

Kılıņ, M., \& Özen, F. (1988a). A5 ve A6 karelerinden yeni floristik kayıtlar. OMÜ Fen Dergisi, 1(2), 75-88.

Kılıņ, M., \& Özen, F. (1988b). Samsun Ondokuz Mayıs Üniversitesi Kurupelit Kampus alanı ve çevresinin florası. OMÜ Fen Dergisi, 1(2), 97-121.

Kökten, K., \& Bakoğlu, A. (2011). Elazığ koşullarında mürdümük (Lathyrus sativus L.)'te farklı sıra arasının tohum verimi ve verim öğeleri üzerine etkisi. Bingöl Üniversitesi Fen Bilimleri Enstitüsü Dergisi, 1(1), 37-42.

Kumar, S., \& Dubey, A. K. (2003). Genetic diveristy among induced mutanst of grasspea (Lathyrus sativus L.). Lathyrus Lathyrism Newsletter, 3, 15-17.

Kuo, Y. H., Bau, H. M., Quemener, B., Khan, J. K., \& Lambein, F. (1995). Solid-state fermentation of Lathyrus sativus seeds using Aspergillus oryzae and Rhizopus oligosporus sp. T-3 to eliminate the neurotoxin ODAP without loss of nutritional value. J. Sci. Food Agric., 69, 81-89.

Kutbay, H. G., Kılınç, M., \& Karaer, F. (1995). Nebyan Dağı (Samsun/Bafra) florası. Turk. J. of Botany, 19, 345-371.

Milczak, M., Pedinski, M., Mnicfiowska, H., Szwed-Urbas, K., \& Rybinski, W. (2001). Creative breeding of grasspea (Latyrus sativus L.) in Poland. Latyrus Lathyrism Newsletter, 2, 85-88.

Öten, M., Kiremitçi, S., \& Erdurmuş, C. (2017). Antalya doğal florasından toplanan bazı mürdümük (Lathyrus sativus L.) hatlarının verim özelliklerinin belirlenmesi. Ege Üniversitesi Ziraat Fakültesi Dergisi, 54(1), 17-26.

Özdemir, S. (2016). Elazığ koşullarında bazı mürdümük (Lathyrus sativus L.) genotiplerinin verim ve kalite özelliklerinin belirlenmesi. (Yüksek lisans tezi), Bingöl Üniversitesi, Fen Bilimleri Enstitüsü, Bingöl, Türkiye.

Pekşen, E. (2005). Samsun koşullarında bazı fasulye (Phaseolus vulgaris L.) genotiplerinin tane verimi ve verimle ilgili özellikler bakımından karşılaş̧ırılması. Ondokuz Mayıs Üniversitesi Ziraat Fakültesi Dergisi, 20(3), 88-95.

Polignano, G. B., Bisignano, V., Tomaselli, V., Uggenti, P., Alba, V., \& Della Gatta, C. (2009). Genotype × environment interaction in grass pea (Lathyrus sativus L.) lines. International Journal of Agronomy, Article ID 898396, doi:10.1155/2009/898396.

Rybinski, W., Szot, B., \& Rusinek, R. (2008). Estimation of morphological traits and mechanical properties of grasspea seeds (Lathyrus sativus L.) originating from EU countries. International Agrophysics, 22, 261-275.

Sabancı, O. C. \& Özpınar, H. (2000). Bazı yem bitkilerinin Menemen koşullarına adaptasyonları üzerine araştırmalar: II. Mürdümük (Lathyrus sativus L.). Anadolu Dergisi, 10(1), 41-45.

Sayar, M. S., \& Han, Y. (2015). Mürdümük (Lathyrus sativus L.) hatlarının tohum verimi ve verim komponentlerinin belirlenmesi ve GGE biplot analiz yöntemiyle değerlendirilmesi. Tarım Bilimleri Dergisi, 21, 78-92.

Sayar, M. S., Han, Y., Seydoşoğlu, S., \& Başbağ, M. (2013, Eylül). Diyarbakır ekolojik koşullarında bazı mürdümük (Lathyrus sativus L.) hatlarının ot verimi, ot verimini etkileyen özellikler ile özellikler arası ilişkilerin belirlenmesi. 10. Tarla Bitkileri Kongresi, Konya.

Seydoşoğlu, S., Saruhan, V., Kökten, K., \& Karadağ, Y. (2015). Diyarbakır ekolojik koşullarında bazı mürdümük (Lathyrus sativus L.) genotiplerinin verim ve verim unsurlarının belirlenmesi. Gaziosmanpaşa Üniversitesi Ziraat Fakültesi Dergisi, 32(3), 98-109.

Şehirali, S. (1980). Bodur Fasulyede Ekim Sıklığının Verimle İlgili Bazı Karakterler Üzerine Etkisi. A.Ü. Ziraat Fakültesi Yayınları: 738, Bilimsel Araştırma ve İncelemeler: 429, Ankara.

Tadesse, W., \& Bekele, E. (2003). Variation and association of morphological and biochemical caharacteristics in grasspea (Lathyrus sativus L.). Euphytica, 130, 315-324.

Talukdar, D., \& Biswas, A. K. (2008). Variability, heritability and scope of selection for some quantitative traits in induced mutant lines of grass pea (Lathyrus sativus L.). International Journal of Plant Sciences, 3(2), 528-530.

Tavoletti, S., Iommarini, L., Crino, P., \& Granati, E. (2005). Collection and evaluation of grasspea (Lathyrus sativus L.) germplasm of central Italy. Plant Breeding, 124, 388-391. 
Tekele-Haimanot, R., Kidane, Y., Wuhib, E., Kalissa, A., Alemu, T., Zein, Z. A., \& Spencer, P.S. (1990). Lathyrism in rural Northwestern Ethiopia: A highly prevalent neurotoxic disorder. Int. J. Epidemiol., 19, 664-672.

Tenikecier, H. S., Orak, A., Gürbüz, M. A., \& Çubuk, M.G. (2017). Trakya Bölgesi koşullarında bazı mürdümük (Lathyrus sativus L.) çeşit ve popülasyonlarının performanslarının belirlenmesi. Kahramanmaraş Sütçü İmam Üniversitesi Doğa Bilimleri Dergisi, 20(Özel Say1), 102-108.

Türk, M., Albayrak, S., \& Çelik, N. (2007). Estimates of broad-sense heritability for seed yield and yield components of grasspea (Lathyrus sativus L.). Turkish Journal of Agriculture and Forestry, 31, 155-158. 